\title{
REPRODUCTIVE PERFORMANCE OF DOMESTICATED BROODSTOCK OF SILVER PERCH, Bidyanus bidyanus (MITCHELL 1838) AND THE RELATIONSHIP BETWEEN OIL GLOBULE FRAGMENTATION AND EGG QUALITY
}

\author{
Sulaeman*\# and Ravi Fotedar*) \\ *) Research Institute for Coastal Aquaculture and Fisheries Extension \\ **) Curtin Aquaculture Research Laboratory, Department of Environment and Agriculture, Curtin University
}

(Received 31 July 2017; Final revised 10 November 2017; Accepted 10 November 2017)

\begin{abstract}
The experiments investigated the reproductive performance of the domesticated broodstock of the silver perch and the relationship between various degrees of oil globule fragmentation and egg quality. Six years old of second generation broodstock $(n=3)$ were evaluated based on the fecundity, fertilisation rate, hatching rate, the degree of oil fragmentation of egg, and the quality of embryos and larvae produced. The fragmentation were grouped into three categories: un-fragmented (cat-1), moderately fragmented (cat-2), and highly fragmented (cat-3). The results showed that the broodstock had a relatively high fecundity $(132,400 \pm 7,22)$, fertilization rate $(94.27 \pm 1.28 \%$, and hatching rates $(87.94 \pm 1.23 \%$. The survival rate of larvae at 12 days post hatching $(\mathrm{dph})$ in cat-1 $(71.3 \pm 0.9 \%$ was higher than cat-2 $(66.7 \pm 0.9 \%$ whereas cat-2 was higher than cat-3 $(61.3 \pm 0.3 \%$. The eggs was dominated by cat- $1(78.11 \pm 2.44 \%$ which was significantly higher than cat-2 $(21.26 \pm 2.45 \%$ and cat-3 ones $(0.40 \pm 0.21 \%$. The survival rate of embryo at 20 hours post spawning (hps) and hatching rate of cat- 1 (95.33 $\pm 0.00 \%$ and $93.33 \pm 0.00 \%$ and cat-2 $(90.00 \pm 0.00 \%$ and $85.00 \pm 0.00 \%$ were significantly higher than cat-3 $(72.33 \pm 1.76 \%$ and $60.33 \pm$ $0.00 \%$. The total length (TL) of the larvae of cat- 1 and cat- $2(8.44 \pm 0.21 \mathrm{~mm}$ and $8.35 \pm 0.23 \mathrm{~mm}$ respectively) were significantly higher than larvae of cat-3 $(7.09 \pm 0.14 \mathrm{~mm})$. No significant difference was found in the larval deformities among any categories. In conclusion, the reproductive performance of six year-old broodstock silver perch showing acceptable performance and egg categorisation based on oil globule fragmentation can be used as a useful tool to indicate eggs quality of silver perch.
\end{abstract}

KEYWORDS: reproductive; oil globule; egg quality; perch; Bidyanus

\section{INTRODUCTION}

Silver perch, Bidyanus bidyanus (Mitchell, 1838) is well known as a potential native species for aquaculture in Australia inhabiting inland waters around the Murray Darling River system (Allan \& Rowland, 2002; Rowland, 2004a). Silver perch has been cultivated for around two decades expecting to be the largest freshwater aquaculture industry in Australia, as declared by Rowland (2009). A number of problems related to the larval production techniques including the understanding of broodstock performance and egg quality still need to be overcome.

\footnotetext{
\# Correspondence: Institute for Coastal Aquaculture Research and Fisheries Extension. Jl. Makmur Dg. Sitakka No. 129, Maros, South Sulawesi 90512, Indonesia.

Phone: + 62411371544

E-mail: bagren_brpbap@yahoo.com
}

Mastery of the techniques of fish reproduction is an important step as it is directly related to aquaculture productivity (Zarski et al., 2011a; Zarski et al., 2011b). Silver perch hatchery has been based on the hypophysation technique to spawn the broodstocks and pond-based larval rearing techniques (Rowland, 1984; 2009). In the hatchery environment, a broodstock can be captured from the natural environment or can be domesticated using farming techniques (Rowland, 2004a). However, Rowland (2009) stated that the performance of the wild-caught broodstock is reduced after five years of continuous spawning.

As the silver perch culture matures and farmers are more familiar with modern farming techniques of the species, some farmers are now able to produce their own larvae (Mccormack, 2017). However, various bottlenecks in pond-based larval culture are 
still challenging farmers as larval quality in pond-based rearing systems cannot be controlled and/or predicted (Mosig, 2005). When domesticated broodstocks used for spawning, the use of hormone and formulated diets, and handling procedures can considerably affect the egg quality and survival of larvae (FernándezPalacios et al., 1997; Almansa et al., 1999; Izquierdo et al., 2001; Watanabe \& Vassallo-Agius, 2003; Targoñska et al., 2010). Eggs that do not develop normally, die after a while, triggering protozoan, and fungal growth that can infect surrounding embryos during incubation (Ciereszko et al., 2009) and then it intensifies during the egg hatching period resulting in mass mortalities due to water degradation (Rowland, 2009).

Egg quality is a complex area to quantify and is still not well understood (Jakobsen et al., 2016). The fatty acid composition of eggs plays an important role in improving reproduction success, including egg quality, and the survival of fry (Komen \& Thorgaard, 2007; Bobe \& Labbé, 2010). Egg quality of silver perch has been identified as a predominant indicator in assessing reproductive success and a key factor causing the high variation in the size of newly hatched larvae (Anonymous, 1999; Moiseeva, 2001; Rowland, 2004b; 2009).

It is widely accepted that egg quality affects both egg and larvae viability which in turn is reflected in several characteristics of larvae including physical deformity, growth rate, mortality rate, and size variability (Zarski et al., 2011b). The difference in individual performance can lead to high cannibalism which, at the end, will directly determine production effectiveness (Rowland, 2009). In silver perch, egg quality is commonly evaluated based on the viability of larvae after hatching (Rowland, 1984; 2009) while earlier determination of egg viability could be a beneficial tool to eliminate low quality eggs leaving incubation of only good eggs quality as in Eurasian perch, Perca fluviatilis (Zarski et al., 2011b).

The distribution of oil globules has been used as an indicator of egg quality in European perch (Zarski et al., 2011b) and brown trout, Salmo truttafario (Mansour et al., 2007). There was no relationship between oil globule distribution in the oocyte and the quality of the eggs especially with respect to reproductive performance of the domesticated rainbow trout (Ciereszko et al., 2009). However, oil globule fragmentation has never been used as a too I to evaluate the reproductive performance of silver perch. The present study was conducted to investigate any relationship between the degree of oil globule fragmentation and the reproductive performance and egg quality of the domesticated broodstock of silver perch.

\section{MATERIALS AND METHODS}

The experiments and the procedure in this study were approved by the Animal Ethics Committee of Curtin University with the approval number of AEC_2011_70 and the Australian Code of Practice for the care and the use of animals for scientific purposes also followed.

\section{Broodstock Source and Preparation}

The experiments were conducted during the summer season which coincided with silver perch maturation time after they were exposed to a low temperature in the winter months in Western Australia. Three pairs of broodstock aged approximately six years with an individual weight range of $1.2-3.1 \mathrm{~kg}$ for males and $2.5-3.7 \mathrm{~kg}$ for females were obtained from Curtin Aquaculture Research Laboratory, Curtin University, Bentley (31⒌'38.26"S 11553'18.09"E). The broodstock were maintained in a semi-closed water recirculating system and fed commercial feed at a rate of $2 \%$ body weight day ${ }^{-1}$ containing $35 \%$ crude protein.

The mature females were marked by the soft and swollen stomach and pink-red genital papilla whereas mature males were marked by the release of the milt when gentle pressure was applied to the abdomen; these were selected for this experiment. The selected mature broodstock were then moved into a 200 litre fibreglass tank and anaesthetised with A-QUIS at 100$120 \mathrm{ppm}$ solutions before hormonal injections. All broodstock were injected intramuscularly with HCG hormone at $200 \mathrm{IUkg}^{-1}$ body weight using a disposable syringe and a $21 \mathrm{G} \times 1.25$ needle to initiate spawning. Each pair of induced broodstock were placed in a 2-ton fibreglass tank until spawning (Rowland, 2004a). The water was vigorously aerated and the water temperature was maintained at $23^{\circ} \mathrm{C}$. The tanks were inspected periodically to observe the spawning. As the spawning was completed, the post spawning broodstock were anaesthetised and weighed before they were returned to the rearing tank. The female weight was used for relative fecundity calculations.

\section{Egg Quality Classification}

Under the stereo microscope, the oil globule was clearly visible, located in the middle of the yolk sac of newly fertilized eggs (diameter range 2.10-2.41 $\mathrm{mm}$ ). The eggs of silver perch were classified based on the oil globule fragmentation following the category stated by Zarski et al. (2011b) with minor modifications. However, only three out of four categories were observed in this research. These categories were: cat-1, a clearly visible, un-fragmented single 
droplet of oil globule, cat-2, several small droplets of the oil globule along with a large one, and cat-3, a highly-fragmented oil globule in the form of several droplets (Figure 1).

\section{Reproductive Performance of the Female Broodstock (Experiment-1)}

The reproductive performance of the broodstock $(n=3)$ was evaluated based on the fecundity, fertilisation rate, hatching rate, and egg categories. The relative fecundity was defined as the number of recently spawned eggs divided by the female body weight (Hunter et al., 1992; Cerdá et al., 1994; Coward \& Bromage, 1999). Fecundity and fertilization percentage were estimated according to established procedure (Panini et al., 2001) with some modifications.

For fecundity determination, the eggs produced by each individual female were initially placed in a 10 litre bucket equipped with aeration from the bottom to provide gentle agitation of the eggs. A subsampling of $10 \mathrm{~mL}$ was taken and the number of eggs were counted before conversion to the bucket volume. The relative fecundity was then calculated and presented as a number of eggs $\mathrm{kg}^{-1}$ female body weight after spawning. At the same time, the fertilization rate was also estimated by counting the num- ber of fertilised eggs divided by the total number of eggs in $10 \mathrm{~mL}$ subsamples.

To determine the hatching rate, eggs from the 10 litre bucket were taken in a $250-\mu \mathrm{m}$ mesh filter and were rinsed with filtered freshwater (Aqua-pure Model-AP12S, 5 microns) and placed in a two litre beaker. A petri dish was used to scoop 100-200 eggs from the beaker which was then placed under a stereoscope. Only fertilized eggs were taken one by one with a pipette and transferred to the wells of the microtiter plates at a rate of one egg per well. The microtiter plates were then covered with a plastic lid, and placed in a controlled-temperature incubator set at $23^{\circ} \mathrm{C}$ until hatching. Using a stereoscope, the number of larvae were counted and the hatching rate was calculated as the number of larvae divided by the number of fertilised eggs initially loaded in the microtiter plates.

To classify the eggs, another sample of $10 \mathrm{~mL}$ in volume were taken from the 10 litre bucket and placed them into five petri dishes $(50 \mathrm{~mm}$ diameter and 12 $\mathrm{mm}$ height). The eggs in the petri dishes were photographed under a stereo microscope using an Olympus SC30 camera with an image acquisition software, getlt, from Olympus Soft Imaging Solutions (Papanikos et al., 2003). The eggs were then classi-

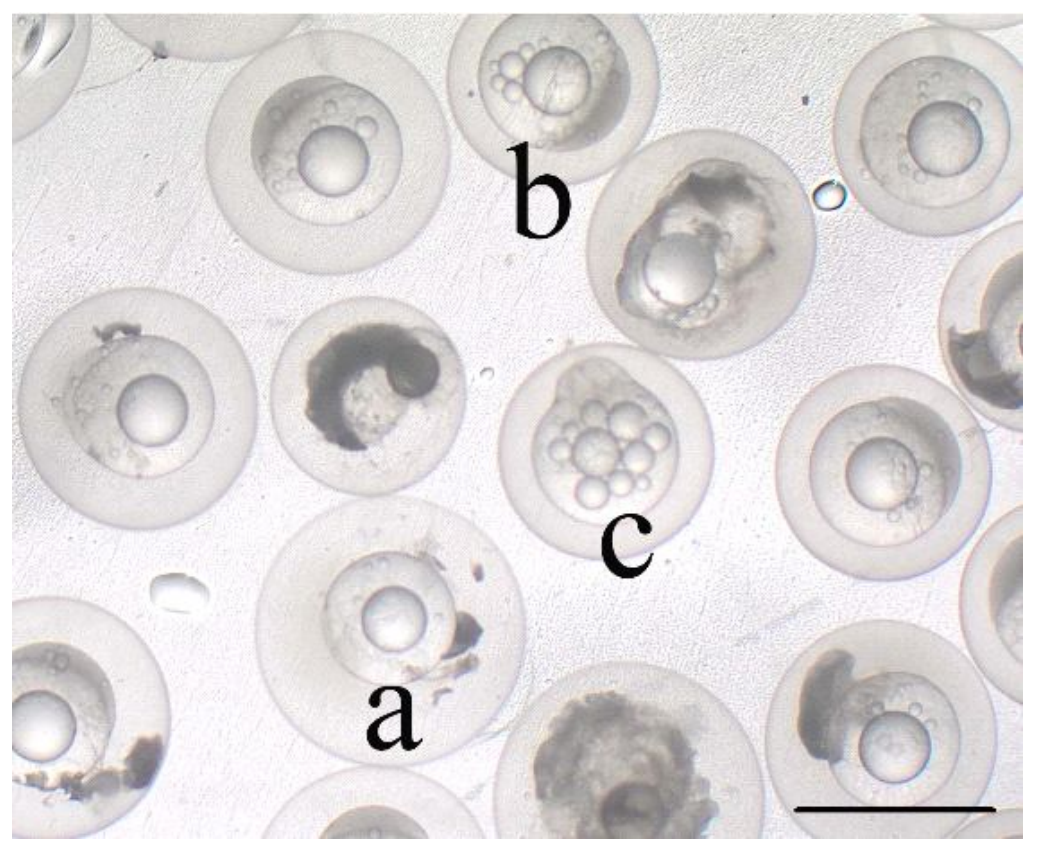

Figure 1. Different categories of ovulated eggs of silver perch with different oil globule fragmentation: category-1 (a), cat-2 (b), and cat-3 (c). Bar= $2 \mathrm{~mm}$. 
fied based on its oil globule fragmentation as explained earlier. From the images, the number of eggs in each egg category of each broodstock was counted and the percentage of egg category was calculated.

\section{The Relationship Between the Degrees of Oil Globule Fragmentation and Egg Quality (Experiment-2)}

\section{Embryo and larval performance at different egg categories}

The eggs from a female were sampled from the 10 litre bucket, as in fecundity determination, using a $250-\mu \mathrm{m}$ mesh filter, rinsed with filtered freshwater, and placed in a two litre beaker (Panini et al., 2001). A petri dish was used to scoop 100-200 eggs from the beaker and was placed under a stereoscope and only fertilised eggs were taken one by one with a pipette and transferred into microtiter plates at a rate of one egg per well. Each egg category was placed in three separate microtiter plates as triplicates. The microtiter plates were then covered with a plastic lid, placed in a controlled-temperature incubator where the temperature was maintained at $23^{\circ} \mathrm{C}$. Using a stereoscope, the survival rate of the embryo from each egg category was calculated at 10 and 20 hour post spawning (hps) and the hatching rate was calculated following the formula: the number of larvae/number of eggs in the microtiter plates $\times 100$. The deformity rate was calculated as the number of larvae with physical deformity/the number of larvae in the microtiter plate.

\section{Effect of egg quality on growth and survival rate}

As soon as the entire batch of eggs were hatched, the larvae from each egg category (section 2.4.) were pooled and placed in five litre cylindrical glassware as stock for a growth and mortality experiments. The glassware was placed in an incubator tank where the temperature was set at $23^{\circ} \mathrm{C}$ as in the incubation temperature.

Two -day-old larvae were randomly taken from each holding glassware (categorised eggs) and placed in one litre beakers at 20 larvae $\mathrm{L}^{-1}$ stocking density in triplicates. Larvae were fed rotifers at a density of 10 ind. $\mathrm{mL}^{-1}$ starting at four days post hatching (dph). The density of rotifers was maintained throughout the experiment by daily adjustments whereas water temperature was set to $23^{\circ} \mathrm{C}$. The faeces and debris, as well as dead fish were removed from the glass beaker every day before feeding and the mortality was recorded. At the end of the experiment at $12 \mathrm{dph}$, the survival rate was calculated while larval growth was determined by measuring the TL $(\mathrm{mm})$ of ten larvae from each egg category.

\section{Data Analysis}

The IBM SPSS 24 and MS Excel 2007 for Windows software were used for the analysis of data and statistical analysis. The data was presented as mean \pm S.E. The data expressed in percent was subjected to arcsine transformation before the statistical analysis was performed. The one way analysis of variance (ANOVA) followed by the Tukey's post hoc test was applied at the significant level less than $5 \%(P<0.05)$ when the analysis of variance revealed statistically significant differences.

\section{RESULTS AND DISCUSSION}

\section{Reproductive Performance of the Female Broodstock (Experiment-1)}

The reproductive performance of the six year-old silver perch broodstock was found to be high as displayed by all studied parameters (Table 1). The relative fecundity was high, ranging from 120,000 to $134.200 \mathrm{~kg}^{-1}$ of bodyweight. Besides, the fertilisation rate and the hatching rate were also high, $94.27 \pm$ $1.28 \%$ and $87.94 \pm 1.23 \%$ respectively (Table 1 ). The relative fecundity per $\mathrm{kg}$ of female of three year-old domesticated silver perch broodstock was 139,286 $\pm 11,405$ as reported by Rowland (2004a), is comparable to the fecundity of the six year-old broodstock $(132,400 \pm 7,218)$ used in the present study (Tabe 1 ). However, the fertilization and hatching rates obtained in this study were much higher than reported by Rowland (2004a) at $84.5 \pm 3.7 \%$ and $76.8 \pm 2.8 \%$ respectively. These different results can be due to different aspects such as age, food, and level of domestication of the broodstock population. Rowland (2004a) used a three year-old F-1 broodstock at first maturation, while in this study, six year-old F-2 broodstock was used. According to Izquierdo et al. (2001), the age of the fish is an aspect that affects reproductive performance, wherein the first maturation commonly results in poor performance than the older fish (Emata, 2003).

The eggs produced by these six year-old broodstock were classified as good quality eggs, since most $(99 \%$ eggs produced were classified as cat- 1 and cat-2. The mean percentage of eggs in cat-1 of $78.11 \%$ was significantly higher $(P<0.05)$ than cat-2 and cat- 3 at $21.26 \%$ and $0.40 \%$ respectively. Other than the egg quality, the results also confirmed that the 
Table 1. Reproductive performance and egg quality composition of silver perch broodstock $(n=3)$ domesticated in a semi-closed recirculation system

\begin{tabular}{|c|c|c|c|c|c|c|}
\hline \multirow{2}{*}{$\begin{array}{c}\text { Broodstock } \\
\text { (female) }\end{array}$} & \multirow{2}{*}{$\begin{array}{l}\text { Fecundity } \\
\text { (eggs kg }^{-1} \text { ) }\end{array}$} & \multirow{2}{*}{$\begin{array}{c}\text { Fertilisation } \\
\text { rate }(\%)\end{array}$} & \multicolumn{3}{|c|}{ Eggs quality } & \multirow{2}{*}{$\begin{array}{c}\text { Hatching rate } \\
(\%)\end{array}$} \\
\hline & & & Cat-1 & Cat-2 & Cat-3 & \\
\hline 1 & 145,200 & 96.38 & 78.16 & 21.31 & 0.50 & 90.38 \\
\hline 2 & 132,000 & 94.47 & 73.87 & 25.48 & 0.00 & 86.48 \\
\hline 3 & 120,000 & 91.95 & 82.30 & 16.98 & 0.71 & 86.96 \\
\hline Average & $132,400 \pm 7,22$ & $94.27 \pm 1.28$ & $78.11 \pm 2.44^{c}$ & $21.26 \pm 2.45^{b}$ & $0.40 \pm 0.21^{\mathrm{a}}$ & $87.94 \pm 1.23$ \\
\hline
\end{tabular}

reproductive performance of domesticated broodstock reared in captivity for about six years was still high as indicated by the high viability of larvae. These findings confront the previous study by Thurstan \& Rowland (1994) who proposed that the fecundity of silver perch broodstock may be reduced after five years reared in captivity.

As in most other cultured fish, silver perch showed segregation in oil globules and this phenomenon is may related to the level of stress occurred during oocyte maturation and spawning process. The process of oocyte maturation is known to incorporate different components such as yolk protein and oil globule (Bromage et al., 1992). Another study showed that the process of maturation can be disturbed by different activities in controlling reproduction such as through hormonal stimulation or the manipulation of environmental conditions (Zarski et al., 2011b). As a result, the segregation of oil droplets during 00 cyte maturation is occurred as has been reported for Perca fluviatilis (Zarski et al., 2011b), Anguilla anguilla (Palstra et al., 2005), Lota lota (Paliñska-Zarska et al., 2014), Salmo truttafario (Mansour et al., 2007), and Oncorhynchus mykiss (Ciereszko et al., 2009). The segregation of oil globules in a different category of fragmentation has been identified as affecting egg quality and regarded as an indicator of egg quality (Zarski et al., 2011b).

\section{The Relationship Between the Degrees of Oil Globule Fragmentation and Egg Quality (Experiment-2)}

The egg quality not only affects embryonic development and their success in hatching, but also affects larvae growth and mortality in the beginning of the developmental stages (Houde, 1974). The survival rate of embryos in all egg categories was high during the incubation period. No mortality was observed until 10 hps and only a few embryos have die at 20 hps. A significant difference in embryo survival from different egg categories was detected at $20 \mathrm{hps}$ (Table 2), whereas no significant difference in the deformity rate among the egg categories was found. The survival rate of eggs in cat-1 and cat-2 showed higher viability than cat-3 eggs as indicated by their high survival rate of the embryo during incubation, especially at $20 \mathrm{hps}$. Further evidence was shown in the hatching rate where only about $60 \%$ of eggs in cat-3, while in cat- 1 and cat- 2 the hatching rate were higher at $93 \%$ and $85 \%$ respectively. Even if the embryo survival and hatching rate differed according to egg category, the frequency of developmental abnormalities was low in each egg category $(0.0 \% 0.5 \%)$ and there was no difference between egg categories. However, the indication of higher deformation at higher oil globule fragmentation, as in cat-3, may indicate that these eggs were of poorer quality than those in cat-1 and cat-2. Zarski et al. (2011b) reported that viability of Eurasian perch eggs at cat-3 was lower compared to cat-1 and cat-2. On the other hand, Ciereszko et al. (2009) reported the inconsistency of the relationship between oil fragmentation and egg quality of rainbow trout where the high fragmentation of the oil globule did not always result in lower egg quality.

According to Abi-ayad et al. (2000), the oil content of eggs is constant during embryogenesis and is not used until the larvae's metamorphosis stage is reached. This means that oil globule fragmentation may not directly affect the survival rate of the embryo during incubation. A mechanism may act as a stressor resulting in higher mortality during the incubation phase and lower the hatching rate of eggs in cat-3. One possible explanation is the process of ovulation is too early and some eggs do not complete the normal final maturation of the oocytes as in category-1 and 2. This explanation is also reported by Zarski et al. (2011b) where early ovulation could 
Table 2. The percentage of survivors of silver perch embryos at different periods of incubation, hatching rate, and the rate of deformity of newly hatched larvae at different categories of egg quality

\begin{tabular}{|c|c|c|c|c|}
\hline \multirow{2}{*}{$\begin{array}{c}\text { Egg } \\
\text { category }\end{array}$} & \multicolumn{2}{|c|}{ Mean survival rate $(\%)$} & \multirow{2}{*}{$\begin{array}{l}\text { Hatching } \\
\text { rate }\end{array}$} & \multirow{2}{*}{$\begin{array}{r}\text { Deformities at } \\
\text { hatching ( } \% \text { ) }\end{array}$} \\
\hline & 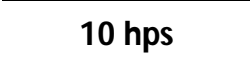 & s & & \\
\hline & 100.00 & $95.33=$ & & $.00^{\mathrm{a}}$ \\
\hline Cat-2 & $100.00 \pm 0.00^{\mathrm{a}}$ & $90.00 \pm 0.00 b^{b}$ & $85.00 \pm 0.00^{b}$ & 0.33 \\
\hline Cat-3 & $100.00 \pm 0.00^{\mathrm{a}}$ & $72.33 \pm 1.76^{\mathrm{a}}$ & $60.33 \pm 0.00^{a}$ & $0.50 \pm 0.003^{\mathrm{a}}$ \\
\hline
\end{tabular}

Note: $\quad$ The data labelled with different superscript in the same column were statistically different $(\mathrm{P}<0.05)$. hps $=$ hour post spawning

have disturbed the final maturation of the oocyte in Eurasian perch which resulted in a low quality of eggs in cat-3 and cat- 4 as indicated by the low survival rate during incubation, low hatching rate, low growth rate, and high mortality of the new larvae.

The visibility of oil globule fragmentation during larval development as noted at $8 \mathrm{dph}$ (Figure2), may suggest that the fraction is permanent until all oil is absorbed completely. This is different from Eurasian perch where the fraction of the oil globule may be merged, partly or totally, immediately after eggs were ovulated and get in contact with water at spawning (Zarski et al. 2011b) and in medaka, Oryzias latipes (Iwamatsu et al., 2008). The oil fragmentation may contribute to the growth and survival rate differences of silver perch larvae from different egg categories. Related to mortality, Li \& Mathias (1982) pointed out that the high mortality of Walleye larvae, Stizostedion vitreum, occurred during yolk sac consumption and complete absorption of oil globules.

The egg quality also affected the TL of the larvae as detected at $12 \mathrm{dph}$. The growth of silver perch larvae was clearly affected by the egg's categories. The TL of larvae in cat-1 and cat-2 (8.4 \pm 0.2 and 8.3 $\pm 0.2 \mathrm{~mm}$ respectively) did not differ significantly $(P>0.05)$, but they were much higher than category$3(7.0 \pm 0.1 \mathrm{~mm})$ at $12 \mathrm{dph}$ (Figure 3). The more fragmented the oil globule, the lower the TL achieved.

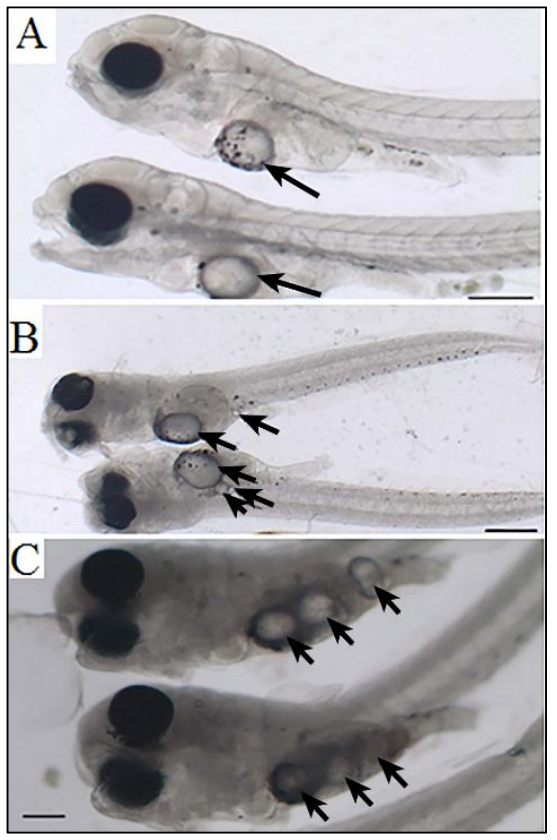

Figure 2. The appearance of oil globule fragmentation of silver perch larvae originating from category I (a), category II (b), and category III (c). Bar $A=500$ $\mu \mathrm{m}, \mathrm{B}=500 \mu \mathrm{m}$, and $\mathrm{C}=200 \mu \mathrm{m}$. 


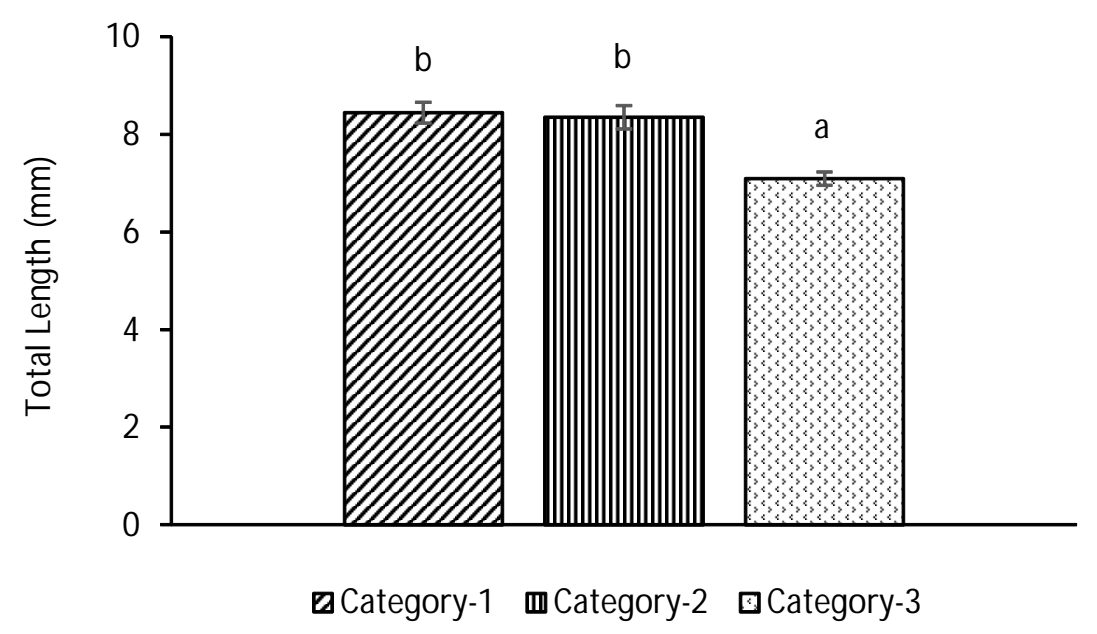

Figure 3. The total length (TL) of silver perch, Bidyanus bidyanus larvae resulting from different egg quality at 12 days post hatching (dph). The same letter over the bars indicates no significant difference $(P>0.05)$.

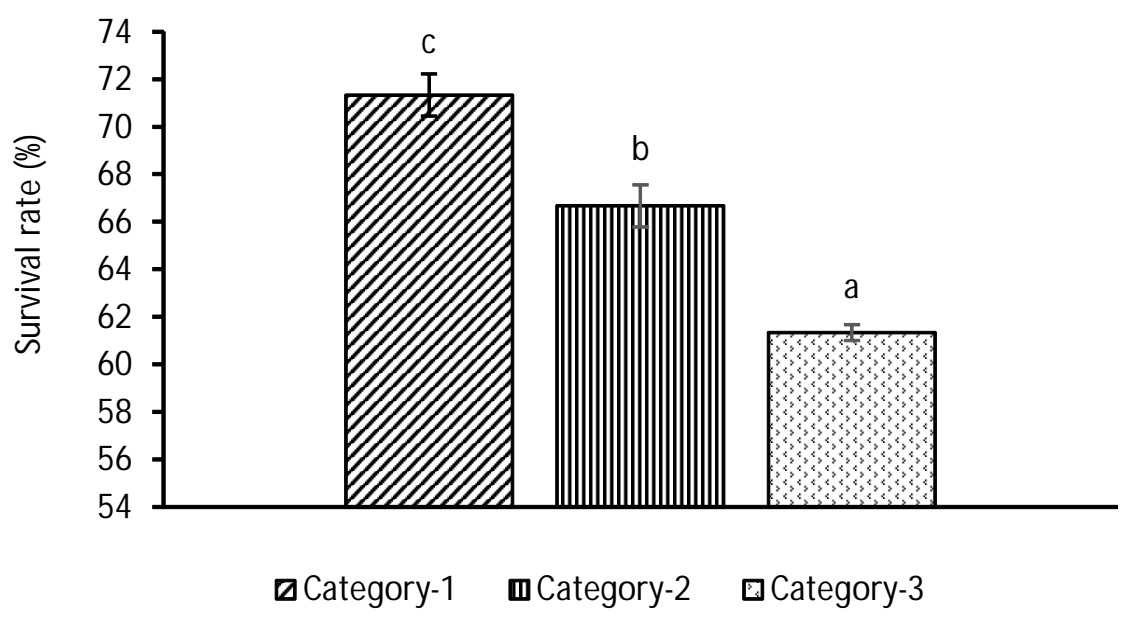

Figure 4. Survival rate (\% of silver perch, Bidyanus bidyanus larvae from different egg categories at 12 days post hatching (dph). Different labels over bars designates significant difference $(P<0.05)$.

The same was true with the survival rate. After 12 days of the rearing period, the lowest survival rate of $61.3 \pm 0.3 \%$ was noted in egg cat- 3 , which was significantly $(P<0.05)$ lower than the survival of cat1 and cat-2 at $71.3 \pm 0.9 \%$ and $66.7 \pm 0.9 \%$ respectively (Figure 4). The survival rate of cat-1 did not show any significant difference $(P>0.05)$ when compared to cat-2. It has been reported that the oil globule contained vitamin $A$ and nutrient ingredients of high caloric value (Iwamatsu et al., 2008), which is crucial for larvae development during the transition from endogenous to exogenous feeding (Iwamatsu et al., 2008). The process of assimilation of fragmented oil globules into the larval body may be obstructed and reflected in small TL and low survival rates at $12 \mathrm{dph}$. This has also been the reason for low viability and high growth variability in Eurasian perch (Zarski et al., 2011b). 


\section{CONCLUSION}

The results suggest that domesticated (F-2) silver perch broodstock reared in captivity for about six years are still viable with acceptable reproductive performance and high quality of eggs. An oil globule fragmentation test is recommended as a valuable tool for evaluating the egg quality in silver perch.

\section{ACKNOWLEDGEMENTS}

The authors would like to acknowledge the Research Institute for Coastal Aquaculture (RICA), Maros, and the South Sulawesi Provincial Government of Indonesia for their administrative and financial support. Special thanks to Simon Longbottom, who kindly provided technical assistance during the laboratory work.

\section{REFERENCES}

Abi-ayad, S.-M.E.-A., Kestemont, P., \& Mélard, C. (2000). Dynamics of total lipids and fatty acids during embryogenesis and larval development of Eurasian perch (Perca fluviatilis). Fish Physiology and Biochemistry, 23, 233-243.

Allan, G.L. \& Rowland, S.J. (2002). Silver perch, Bidyanus bidyanus. In Webster, C.D. \& Lim, C. (Eds.), Nutrient Requirements and Feeding of Finfish for Aquaculture. New York: CABI Publishing, p. 358-373.

Almansa, E., Pérez, M.J., Cejas, J.R., Badýa, P., Villamandos, J.E., \& Lorenzo, A. (1999). Influence of broodstock gilthead seabream (Sparus aurata L.) dietary fatty acids on egg quality and egg fatty acid composition throughout the spawning season. Aquaculture, 170, 323-336.

Anonymous. (1999). Aquaculture potential of Australian native finfish, Fact sheet. Primary Industries and Resources South Australia, $12 \mathrm{pp}$.

Bobe, J. \& Labbé, C. (2010). Egg and sperm quality in fish. General and Comparative Endocrinology, 165, 535-548.

Bromage, N., Jones, J., Randall, C., Thrush, M., Davies, B., Springate, J. Duston, J., \& Barker, G. (1992). Broodstock management, fecundity, egg quality and the timing of egg production in the rainbow trout (Oncorhynchus mykiss). Aquaculture, 100, 141166.

Cerdá, J., Carrillo, M., Zanuy, S., Ramos, J., \& de la Higuera, M. (1994). Influence of nutritional composition of diet on sea bass, Dicentrarchus labrax L., reproductive performance and egg and larval quality. Aquaculture, 128, 345-361.
Ciereszko, A., Wojtczak, M., Dietrich, G.J., KuŸmiñski, H., \& Dobosz, S. (2009). A lack of consistent relationship between distribution of lipid droplets and egg quality in hatchery-raised rainbow trout, Oncorhynchus mykiss. Aquaculture, 289, 150-153.

Coward, K. \& Bromage, N.R. (1999). Spawning periodicity, fecundity and egg size in laboratory-held stocks of a substrate-spawning tilapiine, Tilapia zillii (Gervais). Aquaculture, 171, 251-267.

Emata, A.C. (2003). Reproductive performance in induced and spontaneous spawning of the mangrove red snapper, Lutjanus argentimaculatus: a potential candidate species for sustainable aquaculture. Aquaculture Research, 34, 849-857.

Fernández-Palacios, H., Izquierdo, M., Robaina, L., Valencia, A., Salhi, M., \& Montero, D. (1997). The effect of dietary protein and lipid from squid and fish meals on egg quality of broodstock for gilthead seabream (Sparus aurata). Aquaculture, 148, 233-246.

Houde, E.D. (1974). Effects of temperature and delayed feeding on growth and survival of larvae of three species of subtropical marine fishes. Marine Biology, 26, 271-285.

Hunter, J.R., Macewicz, B.J., Lo, N.C.-h., \& Kimbrell, C.A. (1992). Fecundity, spawning, and maturity of female Dover sole Microstomus pcificus, with an evaluation of assumptions and precision. Fishery Bulletin, 9, 101-128.

Iwamatsu, T., Muramatsu, T., \& Kobayashi, H. (2008). Oil droplets and yolk spheres during development of Medaka embryos. Ichthyological Research, 55, 344-348.

Izquierdo, M.S., Fernández-Palacios, H., \& Tacon, A.G.J. (2001). Effect of broodstock nutrition on reproductive performance of fish. Aquaculture, 197, 25-42.

Jakobsen, T., Fogarty, M.J., Megrey, B.A., \& Moksness, E. (2016). Fish reproductive biology: Implications for assessment and management, $2^{\text {nd }}$ ed. John Wiley $\&$ Sons Ltd, Hoboken, USA.

Komen, H. \& Thorgaard, G.H. (2007). Androgenesis, gynogenesis and the production of clones in fishes: A review. Aquaculture, 269, 150-173.

Li, S., \& Mathias, J.A. (1982). Causes of high mortality among cultured larval walleyes. Transactions of the American Fisheries Society, 111, 710-721.

Mansour, N., Lahnsteiner, F., \& Patzner, R.A. (2007). Distribution of lipid droplets is an indicator for egg quality in brown trout, Salmo trutta fario. Aquaculture, 273, 744-747. 
Mccormack, R.B. (2017). Silver perch, Bidyanus bidyanus: Additional Information. NSW Aquaculture Association Inc. Web site. Retrieved May 24, 2017, from http://nswaqua.com.au/fish-species/silver-perch-bidyanus-bidyanus/.

Moiseeva, E.B. (2001). Protandrous hermaphroditism in Australian silver perch, Bidyanus bidyanus (Mitchell, 1836). The Israeli Journal of Aquaculture, 53, 57-68.

Mosig, J. (2005). Boosting silver perch economics by onfarm breeding. Austasia Aquaculture, 19, 3-7.

Paliñska-Zarska, K., Zarski, D., Krejszeff, S., Nowosad, J., Bilas, M., Trejchel, K., \& Kucharczyk, D. (2014). Dynamics of yolk sac and oil droplet utilization and behavioural aspects of swim bladder inflation in burbot, Lota lota L., larvae during the first days of life, under laboratory conditions. Aquaculture International, 22, 13-27.

Palstra, A.P., Cohen, E.G.H., Niemantsverdriet, P.R.W., Ginneken, V.J.T.v., \& Thillart, G.E.E.J.M.v.d. (2005). Artiûcial maturation and reproduction of European silver eel: development of oocytes during final maturation. Aquaculture, 249, 533-547.

Panini, E.B., Mylonas, C.C., Zanuy, S., Carrillo, M., Ramos, J., \& Bruce, M.P. (2001). Incubation of embryos and larvae of marine fish using microtiter plates. Aquaculture International, 9, 189-196.

Papanikos, N., Phelps, R.P., Williams, K., Ferry, A., \& Maus, D. (2003). Egg and larval quality of natural and induced spawns of red snapper, Lutjanus campechanus. Fish Physiology and Biochemistry, 28, 487-488.

Rowland, S.J. (1984). The hormone-induced spawning of silver perch, Bidyanus bidyanus (Mitchell) (Teraponidae). Aquaculture, 42, 83-86.
Rowland, S.J. (2004a). Domestication of silver perch, Bidyanus bidyanus, broodfish. Journal of Applied Aquaculture, 16, 75-83.

Rowland, S.J. (2004b). Production of silver perch (Bidyanus bidyanus) fingerlings at three stocking densities in cages and tanks. Aquaculture, 229, 193-202.

Rowland, S.J. (2009). Review of aquaculture research and development of the Australian freshwater fish silver perch, Bidyanus bidyanus. Journal of theW orld Aquaculture Society, 40, 291-324.

Targoñska, K., Kucharczyk, D., Kujawa, R., Mamcarz, A., \& Zarski, D. (2010). Controlled reproduction of asp, Aspius aspius (L.) using luteinizing hormone releasing hormone (LHRH) analogues with dopamine inhibitors. Aquaculture, 306, 407-410.

Thurstan, S.J. \& Rowland, S.J. (1994). Technique for the hatchery production of silver perch. In Rowland, S.J. \& Bryant, C. (Eds.), Aquaculture Workshop. Austasia Aquaculture, Grafton and Narrandera, p. 29-39.

Watanabe, T. \& Vassallo-Agius, R. (2003). Broodstock nutrition research on marine finfish in Japan. Aquaculture, 227, 35-61.

Zarski, D., Bokor, Z., Kotrik, L., Urbanyi, B., A. Horváth, A., Targoñska, K., Krejszeff, S., Paliñska, K., \& Kucharczyk, D. (2011a). A new classification of a preovulatory oocyte maturation stage suitable for the synchronization of ovulation in controlled reproduction of Eurasian perch, Perca fluviatilis L. Reproductive Biology, 11, 194-209.

Zarski, D., Paliñska, K., Targoñska, K., Bokor, Z., Kotrik, L., Krejszeff, S., Kupren, K., Horváth, A., Urbányi, B., \& Kucharczyk, D. (2011b). Oocyte quality indicators in Eurasian perch, Perca fluviatilis L., during reproduction under controlled conditions. Aquaculture, 313, 84-91. 